\title{
FRAGMENTOS: SOBRE LA VIOLENCIA ${ }^{1}$ \\ Fragments: On Violence
}

$103-119$

Niklas Bornhauser*

Resumen

La violencia es un fenómeno ubicuo, cambiante y polimorfo. Su análisis requiere de una metodología plural, capaz de dar cuenta de sus singularidades. Se exploran las relaciones entre la violencia, el orden y la ley, con especial consideración de sus vínculos con el lenguaje y la lengua.

Palabras Clave: Violencia, Fragmento, Orden, Ley, Lenguaje, Lengua.

Abstract

Violence is an ubiquitous, changing and polymorphic phenomenon. Its analysis requires a plural methodology, that reflects their peculiarities. The relationship between violence, law and order, with special consideration of the links towards language and tongues are explored.

Keywords: Violence, Fragment, Order, Law, Language, Tongue.

El dominio de las reglas simbólicas, para contar realmente como tal, debe basarse en alguna autoridad tautológica que está más allá de las reglas, que dice "Es así porque yo digo que es así"

Slavoj Žižek, El espinoso sujeto

\section{ACLARACIONES PRELIMINARES}

Las consideraciones subsecuentes, en la medida en que se sostienen en una determinada voluntad de saber, por un lado, resuelta y consciente de sus influjos y antecedentes en un sentido histórico, quedan inscritas en una delgada franja del devenir del debate contemporáneo $\mathrm{y}$, por el otro, en función de sus determinaciones y el emplazamiento resultante, habilitan a efectuar ciertas operaciones conceptuales, y clausurando, en cambio, a otras. Con el propósito de esclarecer — en la medida de lo posible $^{2}$ - el lugar de enunciación, la filiación y la orientación de las reflexiones a ser

\footnotetext{
${ }^{1}$ Artículo elaborado en el marco del Núcleo de investigación DI-446-13/N “Acciones colectivas en Chile (2013-2015)"

${ }^{2}$ Los límites impuestos a dicho intento de esclarecimiento vienen dados no solamente por la expertise, la voluntad e inteligencia de quien emprende la tentativa de elucidación, sino asimismo por la «naturaleza» del objeto o asunto a ser tratado, la episteme del respectivo momento sociohistórico y las vías de comprensión dominantes. Por consiguiente, el sondeo del problema de la violencia, en la medida en que no renuncie a sus pretensiones de saber, está predestinado a ser una genuina exploración de los límites, un escrutinio fronterizo, un sondeo de los confines.
} 
desplegadas, se asume además su sujeción a ciertos principios, que llamamos racionales, epistémicos o gnoseológicos. Debido a la irrefutable imposibilidad de explayarse —en detalle y con la prolijidad que amerita- sobre la aclaración propedéutica del lugar en/desde el cual se escribe (Arno Schmidt), deberá bastar con estas breves indicaciones que apelan a la complicidad del lector en cuanto a lo no dicho y lo no decible del acontecimiento (Er-eignis). Este acontecimiento, recordémoslo, que es la enunciación propiamente tal, depende, entre otros, de su filiación genealógica, sus deudas o lealtades no saldadas, las intenciones - no necesariamente compatibles ni conscientes - que le podamos suponer y la dispersión prolífica de sus posibles interpretaciones. Como anuncia el título, el tema u objeto de estas cavilaciones está constituido $^{3}$ por la violencia, que dada la polisemia y plasticidad del concepto, no es sino un primer guiño a la problemática a ser desenmarañada y no incluye pretensiones de totalidad o exhaustividad. De acuerdo con lo anticipado, más allá de su carácter necesariamente introductorio e incompleto, no se pretende pensar la violencia en sí o como tal, ni de llegar a concluir qué es o podría ser la violencia. Más bien, las cogitaciones siguientes apuntan a problematizar el concepto de violencia a través del adentramiento en el tupido plexo de relaciones de reciprocidad que puedan ser establecidas mediante el ejercicio de la práctica reflexiva, entendida como un quehacer plural, heterogéneo y diverso. Aquella práctica, en cuanto a sus múltiples influencias, se sabe heredera de la llamada Escuela de la sospecha: afinidad que le impone, primero, la tarea de no ceder en cuanto a su insurrección reflexiva o "indocilidad reflexiva" (Foucault, Qu'est-ce, 56), combatiente de toda regulación disciplinar normalizadora; y segundo, su renuncia a todo proyecto explicativo que encarne los ideales herederos de un pensamiento que se desea y piensa a sí mismo como total, universal y absoluto. La convergencia entre sus principales impulsos o ímpetus y sus operacionalizaciones conceptuales se materializa, por un lado en la práctica de la interpretación y, por el otro, en lo que podríamos calificar como su ethos crítico, su convicción irrenunciable no solo de desconfiar de y de desafiar a los modos heredados de pensar, sino de no renunciar a sus aspiraciones más reflexivamente insurrectas a pensar-de-otro-modo. En ese sentido, el desafío de pensar la violencia implica pensar el pensamiento como problematización; es decir, supone aspirar a un pensamiento que no conforme únicamente una reflexión más, por muy erudita y sofisticada que sea, destinada a consagrar los modos anquilosados de pensar, sino que apunte a constituir una experiencia. Quizá habría que agregar que en la medida en que dicha experiencia está abierta a la irrupción de la otredad, de su reverso oscuro, y, además compromete, desde un primer momento, tanto

\footnotetext{
${ }^{3}$ Se emplea, en este lugar, la forma pasiva del verbo constituir, ya que se suscribe el supuesto de que la violencia, lejos de preexistir a su análisis, es constituida como objeto de discurso mediante su respectiva problematización. De este modo, se para de la idea de una violencia constituyente o preconstituida, a la idea de una violencia constituida como resultado de su correspondiente discursivización. Lo anterior no equivale a reducir la violencia al ámbito del discurso, sino simplemente ha de ser entendido como un distanciamiento de toda posición que le suponga a la violencia una naturaleza prediscursiva en el sentido de una originariedad anterior, originaria, natural, ininterrogable.
} 
reflexiva como materialmente, a la potencia pensante, se proyecta como una experiencia transformadora. En otras palabras, en primer lugar el pensamiento no procede de la experiencia, sino que la precede, articula y posibilita; en segundo, a partir de ella se trastoca y se modifica no solo el pensamiento mismo, sino la relación entre el agente pensante y su pensar. En ese sentido, pensar no solo hace posible la experiencia, sino, en estricto rigor, es experimentar. La propuesta, a propósito del desafío de pensar la violencia, sería entonces la de dar pie a la experiencia del pensar, creando las condiciones de posibilidad para la emergencia de una experiencia que ponga en tela de juicio los modos canonizados del pensar y en cuyas fronteras o cuyo más allá se asome - aunque sea a modo de un esbozo fugaz, experimental y transitorio ${ }^{4}$ - un pensamiento alternativo y cualitativamente diferente.

Valgan como antecedente las siguientes consideraciones, hechas por Michel Foucault en la sesión inaugural del día 7 de enero de 1976 en su curso impartido en el Collège de France, titulado Il faut défendre la société. En relación con sus investigaciones anteriores parte advirtiendo de algunos "inconvenientes", en concreto el hecho de que estas, a pesar de su aparente proximidad no habrían alcanzado a llegar a formar un conjunto coherente ni una continuidad apreciable. "Eran investigaciones fragmentarias", dice Foucault, "de las cuales ninguna, finalmente, llegó a su término, y que ni siquiera tenían continuación; investigaciones dispersas y, al mismo tiempo, muy repetitivas, que volvían a caer en los mismos caminos trillados, en los mismos temas, en los mismos conceptos" (Defender, 17). No obstante, lejos de constituir una objeción invalidante, su carácter fragmentario y disperso hace parte de una convicción metodológica: "después de todo, se trataba de pistas a seguir, importaba poco a donde condujesen, incluso era importante que no condujesen a ninguna parte, que no tuviesen de antemano una dirección determinada" (17). Más que reprocharles a dichas investigaciones su falta de unidad y coherencia, de lo que se trata es de rescatar lo que a los ojos de los defensores de la lógica impuesta por los grandes métarrecits podría parecer justamente su mayor defecto: a saber, su carácter fragmentario. Es decir, se propone recortar el problema de la violencia mediante una metodología singular, particular, no universal, en suma, una metodología del fragmento. Una metodología que reivindica los saberes locales, intermitentes, discontinuos, deslegitimados por el canon científico imperante y sus pretensiones de conformar el único modo de conocimiento verdadero. La metodología del fragmento se opone a cualquier intento por hablar en nombre de los derechos de una ciencia única, con alcances universales y se resiste a aceptar, sin más, la hegemonía de un discurso unitario, formal y, en rigor, científico en el sentido "verdadero".

Las razones para dicha elección guardan relación con la convicción que el abordaje de la violencia, si no quiere incurrir, a su vez, en la violencia metodológica,

\footnotetext{
${ }^{4}$ Léanse dichas características como un parafraseo de la primera mitad del conocido enunciado de Charles Baudelaire a propósito de la Modernidad: "La modernité, c'est le transitoire, le fugitif, le contingent, la moitié de l'art, dont l'autre moitié est l'éternel et l'immuable" (884).
} 


\section{Niklas Bornhauser}

debe abstenerse de toda explicación con pretensiones de universalidad y de totalidad. La violencia, por consiguiente, si es que no quiere volverse objeto de la violencia, requeriría de un abordaje particular, sensible a las constelaciones en las cuales se materializan las relaciones de saber-poder, capaz de mantener una actitud crítica ante la imposición de grillas interpretativas prefabricadas, avaladas por la tradición del pensar y el consenso reinante en ciencias. En este caso, la violencia ejercida por los sistemas totalitarios nos advierte sobre el peligro de incurrir en explicaciones de la violencia con pretensiones de totalidad. El ensayo con una metodología que hemos denominado - a falta de un término mejor - del fragmento, obedece a las consecuencias de las consideraciones precedentes.

Por ende, como nos permiten conjeturar los pasajes evocados, dicha metodología convoca un modo particular del caminar del pensar, Denkweg: el de un pensar un camino que es experiencia, un tránsito oscilante, pendular, que otea de lado a lado; un pensar que recorre hasta sus extremos, sin medir las consecuencias, cada una de las dimensiones del problema intempestivamente desocultadas, trazando de este modo la huella vacilante de un ir hasta el límite de lo pensable y de lo posible. Las aspiraciones de semejante pensamiento serían, nada menos, que llegar hasta el límite del saber y de lo consabido, hasta donde este se encuentra con algo otro, impermeable, opaco, radicalmente diferente, que no estaba contenido - ni siquiera como posibilidad o en potencia - en sus condiciones de partida; hasta el límite del poder, donde este choca inapelablemente con una resistencia éxtima, extrínseca, irreductible a las entramadas mallas de las relaciones de poder; hasta el límite de la subjetividad, donde esta, alejada de sus dominios más confortables y seguros, se ve enfrentada con la posibilidad cierta de su aniquilación.

\section{MAPA DEL ARGUMENTO}

Si hacemos el esfuerzo de trazar una cartografia tentativa del argumento a ser desplegado, los principales momentos de aquel pensar se presentan en los siguientes hitos: en primer lugar examinar lo que podría llamarse el círculo de la violencia, una rueda dentada en que su relación con el orden sociosimbólico tiene una función central para la dinámica que sostiene a dicha figura. El mentado escrutinio se efectuará estudiando los principales pronunciamientos de Sigmund Freud y Wolgang Sofsky al respecto. En segundo lugar, se harán algunos alcances etimológicos respecto de los trazos del vocablo Gewalt en el idioma alemán, contrastando su derrotero con los caminos emprendidos en la lengua castellana. Tercero, se discutirá lo que designamos como rupturas del círculo, sus quiebres o desgarros: aquellas consideraciones que recogen los principales hallazgos de los momentos anteriores y que le asignarán un lugar destacado a las reflexiones de Georges-Arthur Goldschmidt sobre l'impensé radical.

Si bien por razones metodológicas dichos instantes (Augenblicke) a lo largo del escrito se presentan como si fuesen soplos del pensar separados y autónomos, no por 
ello constituyen una secuencia lógica estricta ni continua, que pretenda anticipar sus propias conclusiones de modo definitivo. Es decir, su orden - derivado, secundario, impuesto, consciente de su carácter forzoso y arbitrario - es una mera propuesta problematizante para instalar, de modo provisional y tentativo, una hipótesis comprensiva abierta y productiva, articulada contingentemente por fragmentariedad e instantaneidad de sus relámpagos del pensar.

\section{DESARROLLO, PROPIAMENTE TAL}

a. Sobre los relatos de los orígenes: Érase una vez

Los diversos relatos de los orígenes - aquellas Ursprungserzählungen de las cuales tanto nos advertía Friedrich Nietzsche - sientan las bases para pensar que la violencia y el orden establecen entre sí una relación espinosa e imbricada que bien podría calificarse de dialéctica. El punto de partida, fijado a posteriori mediante la respectiva ficción retroactiva, sería el siguiente: en los comienzos, antes de la introducción implacable de la fuerza reguladora de la diferencia, cuando los hombres aun eran indistintos, libres e iguales, nadie podía estar seguro — ni de la naturaleza, ni del otro- del Nebenmensch freudiano, ni de sí mismo. En aquellos tiempos inmemoriales gobernados por el caos y la anarquía pulsional, según testimonian dichos relatos, el afecto más frecuente y acertado sería la angustia de aniquilación. El resto del cuento es conocido: asesinato del padre primordial, banquete totémico y finalmente retorno del padre muerto. De acuerdo con Freud, las principales características de este padre son: primero, ser más fuerte que el padre en vida y segundo, inmortal, ya que en la medida en que es un padre muerto, ya no puede ser matado.

El retorno del padre muerto, prosigue el relato, crea las condiciones de posibilidad para el advenimiento de un momento crucial en aquella leyenda un instante capaz de introducir inapelable e irreversiblemente la brecha que separaría el antes del después; a saber, el primer pacto, destinado a proteger a los hombres, primero de la naturaleza; segundo de ellos mismos; y tercero de toda transgresión a la ley en general. Sin embargo, el establecimiento de dicho contrato, destinado a regular y prescribirle a los hombres qué deben hacer - y qué no- resultaría ser un arma de doble filo: por un lado, la imposición de la ley, en la medida en que está orientada a regular, encauzar y sofocar a las pasiones, es a su vez, violenta; por el otro, toda regulación mediante leyes, si bien por un lado suprime o sanciona ciertas acciones, por el otro produce sus propias transgresiones, inexistentes con anterioridad a la formulación de la ley en cuestión.

Se puede hablar, por ende, de un círculo vicioso, es decir, un dialelo o una "pescadilla que se muerde la cola", establecido entre el orden cultural y la violencia: dicho círculo no narra el término definitivo de la violencia, su domesticación y control absoluto, sino que describe el desplazamiento de esta en tres tiempos, a los cuales ya Freud nos tiene acostumbrados: primero la violencia primordial, Urgewalt, una conjetura conceptual necesaria que comparte con otros términos freudianos - Urvater, Urverdrängung, Urhorde - su carácter originario, primigenio e inaugural; en segundo 


\section{Niklas Bornhauser}

lugar la violencia propiamente tal, así como la conocemos en sus múltiples manifestaciones contemporáneas en diversos escenarios: en los estadios, en las calles, en las casas, etcétera; tercero, el retorno de la violencia bajo su forma disfrazada, desfigurada, capaz de engañar a la conciencia moral y de sortear los diques de la represión. De este modo, el relato de la violencia se convierte en la descripción de un principio plástico, móvil: sus metamorfosis, el permanente cambio de sus formas.

\section{a.1. Excursos: Sendas, desfiladeros y caminos del pensar}

I) Como recuerda Slavoj Žižek en El espinoso sujeto. El centro ausente de la ontología política (2001), según Michel Foucault la relación entre la prohibición y el deseo - en este caso, deseo de violencia (o violencia de deseo) - es circular y absolutamente inmanente. En efecto, la lectura atenta de textos como El poder psiquiátrico (2005), Defender la sociedad (2000), El sujeto y el poder (2001) permite conjeturar que el poder y la resistencia, es decir, el contrapoder, la rebeldía o indocilidad frente al poder, se presupondrían y generarían recíprocamente: en otras palabras, las mismas medidas prohibitivas que identifican, nombran clasifican y regulan los deseos ilícitos, en realidad los fundarían y concebirían. Dicha correlación entre prohibición y deseo lleva a postular que los mecanismos del poder — como partes de la sujeción anatomopolítica del cuerpo individual o de la administración biopolítica de la población - en lugar de apuntalarse en un ente preexistente, más bien producirían ellos mismos el objeto sobre el cual ejercen su fuerza. La virtuosa circularidad inherente a dicha figura lógica se repite en el campo de las teorías contemporáneas de subjetivación (assujettissement), como ha demostrado Judith Butler (1997), quien sostiene que el sujeto en tanto sujeto de ley, súbdito o vasallo, no puede ser pensado exclusivamente como aquel ente que en un segundo instante es oprimido por el poder, sino que sería la emergencia resultante de esa opresión. De este modo el sujeto desustancializado desprovisto de toda esencialidad anterior a su complejo proceso de constitución, y por medio de su permanente producción se inscribe incesantemente en un complejo entramado de relaciones de poder, a partir del cual se vuelve posible y del cual depende su existencia. En palabras de Judith Butler: "los mismos mecanismos disciplinarios ponen en marcha una proliferación salvaje de lo que intentan suprimir y regular: la represión misma de la sexualidad suscita nuevas formas de placer sexual (...) La ley represiva no es externa a la libido que esa ley reprime, sino que la ley represiva reprime en la medida en que esa represión se convierte en actividad libidinal" (Butler, 9). Es decir, la difundida idea de una oposición excluyente entre el deseo y la prohibición, entre el sujeto (de deseo) y la ley, más que una realidad irrefutablemente cierta resulta ser una quimera, una ilusión o un prejuicio destinado a descaminar todo intento de problematización de dicha relación. En el caso de la violencia, el popular antagonismo entre el ámbito anómico y salvaje de la violencia, y su regulación mediante la ley deviene un supuesto al menos problemático, que requiere ser examinado críticamente. 
II) Como ejemplo de la imbricada relación entre ley y violencia —que, de acuerdo con lo desarrollado, dista de ser una relación simple, determinista o linealvalga recordar las Leyes del 7 de abril 1933, conocidas como Gesetz zur Wiederherstellung des Berufsbeamtentums o Ley de restablecimiento del estamento de los funcionarios públicos. En la ley en cuestión - concretamente, en el $\S 3$, también conocido como Arierparagraph - se establece quiénes serán considerados funcionarios públicos de descendencia no aria: a saber, quiénes tendrían al menos un abuelo o abuela judío. Posteriormente, en las Leyes de Nürenberg, conocidas como Nürnberger Rassengesetze o Ariergesetze, se formularon la Ley de protección de la sangre y del honor alemanes (Gesetz zum Schutze des deutschen Blutes und der deutschen Ehre) y la llamada ley de ciudadanía del Reich (Reichsbürgergesetz); en ambos casos se trata de leyes violentas, brutales, leyes que avalan, transmiten y potencian la violencia en vez de prevenir o suprimirla.

En lugar de suprimir o encauzar la violencia, dichas leyes abrieron el camino para la instauración del "orden del terror", que no solamente hizo posible el surgimiento del Tercer Reich, sino que es probable que sea uno de los factores decisivos para la consolidación y perpetuación del nacionalsocialismo. En el análisis de Sofsky se pueden rastrear las influencias de la fenomenología social, la antropología filosófica de Helmuth Plessner, la sociología de Georg Simmel y la antropología de Elias Canetti pueden distinguirse al menos dos momentos: El primero de ellos, asociado a textos como Die Ordnung sozialer Situationen. Theoretische Studien über die Methoden und Strukturen sozialer Erfahrung und Interaktion y Die Ordnung des Terrors: Das Konzentrationslager, está fuertemente centrado en el problema del orden y sus consecuencias para la experiencia y la estructuración subjetiva. Su estudio sobre el campo de concentración no solamente distingue a este como un producto específicamente moderno, concebido de acuerdo con la racionalidad moderna, sino que lo subraya como la implementación de un orden deshumanizante, silencioso, contrario a toda manifestación estridente de violencia, que crearía las condiciones de posibilidad para la implementación de un nuevo modo de matar. El segundo de ellos, conformado por Traktat über die Gewalt (1996), analiza las relaciones entre el orden(amiento) cultural y la violencia, pasando por la consideración de aspectos como la pasión, la angustia, el dolor, la tortura y la ejecución. La hipótesis central de dicho libro retoma el razonamiento de Thomas Hobbes formulado en el Leviathan y recorre diversos escenarios que van desde la ejecución de Gilles de Rais hasta la Revolución francesa. Zeiten des Schreckens. Amok, Terror, Krieg (2002), el segundo libro que integra este momento, consiste en una serie de ensayos agrupados en torno a cuatro ejes titulados: "Más allá de la frontera", "Terror y persecución", "Guerra" y "Repercusiones". Por sobre la singularidad de los análisis pormenorizados propuestos en cada uno de los ensayos, hay un denominador común que los atraviesa: el resuelto rechazo de cualquier teoría "global" sobre las causas posibles de la violencia y la férrea defensa de la descripción y comprensión detallada de formas y situaciones concretas y singulares de violencia. 
Sus análisis del campo de concentración, pertenecientes en lo fundamental al primer momento, se basan tanto en los testimonios de los sobrevivientes como en el análisis de la estructura y de las prácticas habituales de los campos. En ellos Sofsky describe los efectos de los mecanismos de "poder absoluto" sobre la existencia humana. En la medida en que el campo se configura como una extranjería interna (inneres Ausland) (Freud, 66) que se rige por una lógica autorreferente y endógena, categorías como espacio, tiempo, trabajo o estructuras sociales perderían toda función de orientación de lo humano. En relación al problema de los campos ${ }^{5}$, siguiendo en este punto el trabajo de Giorgio Agamben, resulta crucial pensarlos no como un accidente casual y fortuito perteneciente a un pasado ya prescrito, una anomalía azarosa ya superada, sino como a la matriz fundante, no siempre explícita, como el nomos del espacio político en el cual habitamos. Su interés no recae solo en la materialidad del campo, en su inclemente facticidad, sino en como éste, en tanto consecuencia de ciertas rearticulaciones en el campo de la ley y del derecho, no solo se tornaría posible, sino que incluso se volvería legítimo hasta el punto de posicionarse más allá de todo cuestionamiento. A propósito de los escenarios legales que habilitaron el camino para la implementación de los campos, Agamben en Estado de excepción (2004) identifica un antecedente relevante para pensar este problema: la llamada custodia protectora: Schutzhaft $t^{6}$. Advierte en el hecho que la base jurídica de la internación forzosa no habría sido el derecho común, sino la custodia protectora, una institución jurídica — de forzada o tergiversada derivación prusiana - que bajo el nacionalsocialismo habría hecho parte de una especie de práctica policial preventiva en tanto habría permitido "poner bajo custodia" a los individuos. La aludida Schutzhaft se habría desentendido de cualquier contenido relevante en lo penal con el único objetivo de evitar cualquier amenaza o peligro para la seguridad del Estado. La protección (Schutz) de la libertad que se pone en juego en el arresto o en la reclusión (Haft) es, irónicamente, protección contra la suspensión de la ley que caracteriza a la emergencia. Como advierte de inmediato Agamben, la novedad consiste en el hecho de que la llamada custodia o detención protectora - con toda la serie de acciones, medidas y procesos que ella habilita y legitima - una vez que logra desprenderse del estado de excepción, sobre el cual se fundaba en un inicio, devendría la situación normal, usual, en cuya anomalía ya nadie repararía ${ }^{7}$."El campo", en palabras de Agamben, "es el espacio que se abre cuando el

\footnotetext{
${ }^{5}$ A pesar de que se han distinguido campos de reclusión, de traslado, de trabajo, de concentración y de exterminio, entre otros, las reflexiones están referidas sobre todo a los campos de concentración (Konzentrationslager).

${ }^{6}$ Los orígenes de la Schutzhaft apuntan a la ley prusiana sobre la «protección de la libertad personal» (Schutz der persönlichen Freiheit) del 12 de febrero de 1850 y la ley prusiana del 4 de junio de 1851 sobre el estado de sitio, que en 1871 se estableció en toda Alemania (con excepción de Baviera). No obstante, la aplicación de la ley por los nazis implicó una importante torsión o lectura orientada a fines, a contrapelo de la formulación original de dichas leyes.

${ }^{7}$ Cuando en marzo de 1933 Heinrich Himmler decide crear en Dachau un "campo de concentración para prisioneros políticos", este fue inmediatamente confiado a las SS y, mediante la Schutzhaft, puesto fuera de las reglas del derecho penal y del derecho carcelario.
} 
estado de excepción comienza a devenir la regla. En ese momento el estado de excepción, que era en esencia una suspensión temporal del ordenamiento, adquiere un orden especial permanente que, como tal, permanece, sin embargo, constantemente fuera del ordenamiento normal" (Agamben, en línea).

El estatuto del campo en cuanto espacio de excepción ${ }^{8}$ es absolutamente paradójico, ya que se trataría de una parcela del territorio, cuidadosamente recortada sobre el fondo, a la cual se emplazaría fuera del ordenamiento jurídico normal sin que por ello sea reducible a un simple espacio externo. Como dice Agamben, "lo que allí dentro está excluido es, según el significado etimológico del término excepción (excapere), puesto fuera, incluso a través de su propia exclusión" (Agamben, en línea). De acuerdo con lo que se desprende de la palabra alemana Ausnahmezustand, se trata de un estado (Zustand) de excepción (Ausnahme) que coge o toma (nehmen) algo, colocándolo en el exterior, afuera, exceptuándolo (ausnehmen) de toda sujeción al ordenamiento legal. Dicha figura puede servir para pensar, por un lado, el círculo antes aludido entre orden y violencia; y por el otro, para hacerse una idea sobre cómo entender o incluso promover los quiebres en dicho entramado referencial: es decir, sobre cómo contribuir a crear las condiciones de posibilidad favorables para que se produzcan las rupturas ineluctablemente inesperadas e inesperable en un tejido en apariencia homogéneo y exhaustivo, gobernado por una regularidad que no admite excepciones y, al mismo tiempo, las convierte en norma. El análisis de esta figura revela que la sustracción al ordenamiento imperante implica, a su vez, una captación por el mismo, ya que el propio estado de excepción en tanto función pasa a formar parte del ordenamiento en cuestión. La conclusión, para Agamben, es que si no se emprende el intento por descifrar esta particular estructura jurídico-política que precede y subyace a los campos y cuya vocación no es otra sino asegurar de modo estable la excepción, lo sucedido en los campos permanecerá ininteligible en un punto crucial. En este sentido, la violencia — en un principio inequívocamente perturbador e ilegítimo- encontraría su cobijo en la figura del estado de excepción, partícula que deviene fundamental no solo para explicar los campos de concentración nazis, sino para desentrañar el ordenamiento cultural contemporáneo y su dificultosa relación con la herencia moderna.

\section{b. Alcances etimológicos}

Una primera lectura de lo ya expuesto podría inducir a pensar que se trata de una contribución a un pensamiento borroso, universalizante e indiscriminado, que afirmase de modo categórico, desmintiendo o desconociendo la existencia y validez de toda diferencia: "todo es violento". Valga la aclaración que se trata de todo lo contrario, ya que con miras a su comprensión no es solo posible sino estrictamente necesario establecer ciertas distinciones respecto de la idea de violencia. El territorio al interior del

\footnotetext{
${ }^{8}$ En italiano o en francés se habla de "decretos de urgencia" o "estado de sitio", stato di emergenza o état de siège, mientras que en inglés se usa martial law y emergency powers.
} 
cual es posible establecer dichas distinciones y de delimitar el término mediante el establecimiento de las diferencias sobre el fondo de lo mismo y la actualización de sus relaciones de sinergia y de oposición es, por supuesto, el lenguaje. A partir del momento en que ya no se adhiere a la perspectiva trascendental kantiana respecto del conocer y se abandona la universalidad de las formas de la razón, la particularidad de las formas de la lengua deviene clave indispensable de la síntesis de la experiencia. Dicho proceder es consistente con la convicción que el lenguaje no actuaría sobre determinados objetos previamente constituidos y ya plenamente percibidos, sino que incide decisivamente en su forjamiento y representación. "Al concebir el lenguaje como un principio activo que impone su síntesis para la captación de los fenómenos, la forma lingüística y el contenido objetivo de la experiencia aparecen condicionados. Es decir, la forma lingüística no podría separarse de los contenidos del pensar; no habría ideas claras y distintas susceptibles de ser contempladas por una mirada interior muda" (Claro, 21). De ahí en adelante el lenguaje adquiere un innegable papel protagónico en cuanto a la mediación y determinación no solo del pensamiento, sino de toda la síntesis de la experiencia de sí mismo y del mundo. Una vez planteada la inseparabilidad entre pensamiento y lenguaje, resulta innegable que el hombre convive con los objetos dispuestos en su mundo como el lenguaje se los trae. Andrés Claro, en El contrato de transporte y el naufragio del sentido: las concepciones lingüistico-trascendentales de $W$. von Humboldt, recuerda la segunda concepción fundamental de Humboldt para la evaluación de todo transporte semántico: "El pensar no depende meramente del lenguaje en general, sino, hasta cierto grado, también de cada lengua determinada y singular... Una parte muy significativa del contenido de cada lengua depende de ella tan indudablemente que la expresión lingüística no puede ya continuar siendo indiferente para el contenido" (Humboldt en Claro, 21). Por ende, cada lengua en la medida en que posee y es deudora de una forma interna y un carácter propios, producirá cortes y síntesis particulares de lo fenoménico, conformando de este modo una visión de mundo no solo distinta e inconfundible sino, incluso, inconmensurable con las demás. Añádase al hecho que cada lengua abre (erschliesst) el mundo a su manera irreproduciblemente singular la convicción de que ninguna de ellas goza de privilegios o ventajas sobre otra, por lo que la elección del idioma no presupone un acceso privilegiado a la verdad ni su reverso. En este caso, las cavilaciones siguientes, destinadas a rastrear la inscripción arqueológica de las enrevesadas sendas del vocablo, se asentarán en la lengua alemana.

La expresión alemana Gewalt, según el diccionario de los hermanos Grimm, se remonta a los verbos giwaltan, giwaldan, o al anglosajón, geweald, wald (en el sentido de power, strength, might, efficacy). El campo de significación asociado incluye además palabras como empire, rule, dominion, mastery, sway, jurisdiction, government, protection, keeping, a bridle-bit, potestas, facultas. Bosworth, Toller y Northcote, en An Anglo-Saxon Dictionary (1898), lo remite a weald, power. Asimismo abundan diversas pistas que apuntan al nórdico antiguo: vald (poder, violencia, fuerza, causa). En el Beowulf, el simplex aparece en múltiples contextos y relaciones con las significaciones de "tener la fuerza de", "poseer poder sobre", "disponer de algo", 
“dominar algo". Los orígenes del término Gewalt (Röttgers y Saner, 45) remiten a la raíz indogermana val (latín valere), cuya forma verbal giwaltan, waltan, originalmente significaba "poseer la facultad de disponer de algo". En ese sentido remite a una facultad: ya sea una capacidad o aptitud natural, física o moral, o bien a la autoridad o derecho que tiene alguien para hacer algo. Pero también ese hacer implica el acto de colocar, poner o instalar. El dicho alemán Schalten und walten, que literalmente se traduce como: "mandar/accionar y obrar/actuar", se emplea para designar una situación en la cual alguien posee la soberanía para "hacer su voluntad" como corresponde a su deseo. Implica cierta potencia, autoridad o señorío, pues sugiere la libertad de actuar conforme a su anhelo sin restricciones algunas. El acto en cuestión no se encuentra con un estado de cosas inmaculado, una especie de tiempo cero, sino que recae sobre un determinado estado de cosas que es sostenido en sus respectivas relaciones de poder. Gewalt no se inclina hacia las acciones conservadoras empeñadas en perpetuar el statu $q u o$, ni hacia las acciones revolucionarias interesadas en proponer una vuelta o torna en contra de la distribución de poderes consolidada. En otras palabras, la naturaleza de dicho giro - si es reaccionario o subversivo, pacífico o violento, indulgente o belicoso- queda en suspenso sin inclinarse o predisponer hacia ninguna de las dos opciones.

A diferencia de lo que acontece en otras lenguas, Gewalt no hacía alusión a un término legal, sino que designaba precisamente aquel ámbito de la libertad que era omitido o exceptuado por la ley. Su significación primordial guarda relación con "ser capaz de" y alude a la capacidad o facultad de poder ejecutar una acción sin anticipar juicio alguno sobre su legalidad o legitimidad (Heitmeyer y Hagan, 2002). Si nos remitimos a sus raíces etimológicas, el concepto designa el poder-disponer de los entes intramundanos, esto es, el decretar o conducirse en relación con un campo - más o menos abierto - de posibilidades. Esta acepción en el sentido de capacidad de realizar una acción se conserva en una serie de expresiones contemporáneas como Verwaltung, administración, Sorgfalt walten lassen, cuidar de, velar por, walten und schalten, operar y actuar, etc ${ }^{9}$.

Por consiguiente, la expresión Gewalt reúne dos conceptos parciales y separados: por un lado, potentia, potestas y dicio, que se derivan de la delegación, el encargo o mandato, en el sentido de dominio, potestad o influencia; y, por el otro, vis y violentia que designan un amplio espectro de significaciones que van desde la pujanza o la fuerza hasta la violencia física cruda, incluyendo el llamado Faustrecht, la ley del

\footnotetext{
9 A fines del Medievo y comienzos de la llamada Neuzeit, se pueden distinguir al menos cuatro variaciones, no necesariamente excluyentes ni incompatibles, de Gewalt: Primero, la alusión al gobierno público, atado a un orden legal, como ocurre en Staatsgewalt, entendido como el ejercicio de poder soberano al interior de un territorio asociado a un estado mediante sus órganos e instituciones, o Gewaltenteilung, separación o división de poderes, como lo postula la trias politica. Segundo, la designación neutra de autoridades territoriales, respectivamente, de los representantes de los poderes de Estado. Tercero, la relación de disponibilidad o relación efectiva de propiedad. Cuarto, el uso físico de violencia, coerción en el sentido político, acciones violentas aisladas en el sentido de vis o violentia.
} 
más fuerte. Esta última es una acepción extrema de Gewalt que se sitúa más allá de toda constitucionalidad o dignidad humana, inscribiéndose en un reino oscuro y hermético, ajeno y al mismo tiempo propio del ordenamiento simbólico. Su traducción al castellano, según las circunstancias, sería "violencia", "poder" o "fuerza".

\section{b.1. En los confines, Fronteras de su significación}

El problema de la exploración de las etimologías, el levantamiento de los campos de significación asociados y la delimitación de los usos vinculados a la palabra en el lenguaje nos confronta tarde o temprano con un problema que se emplaza en los límites de aquel quehacer: la traducción. Los siguientes ejemplos, más allá de su carácter rudimentario y parcial, acaso puedan ilustrar los desplazamientos y tránsitos de sentidos de la Gewalt en las lindes de las respectivas lenguas.

El pasaje subsecuente, extraído de El Evangelio según San Mateo, originalmente

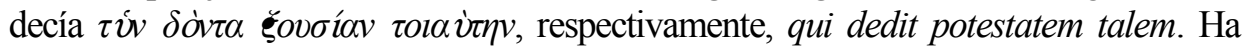
sido traducido al castellano como "Y la gente, al verlo, se maravilló y glorificó a Dios, que había dado tal potestad a los hombres" (Versión Reina Valera, 1960, Matt, 9:8). Mientras que las primeras traducciones al althochdeutsch decían der da gab solchen gewalt den menschen, Luther ${ }^{10}$ traduciría el pasaje en cuestión del siguiente modo: "der solche macht den menschen gegeben hat". O sea, potestatem, que remite a potestas, es traducido al alemán ya sea como Macht, poder, o como Gewalt, violencia.

A su vez, como consta en Deutsches Wörterbuch von Jacob und Wilhelm Grimm, el fragmento ih bin man untar giwelti, homo sum sub potestate, que corresponde al mentado evangelio, ha sido traducido como: "thoh ic undar geweldi sî adalcuninges. Heliand 2113; ich bin ein man geschikt von der gewalt cod. Tepl.; under dem gewalt. Augsburger bibel von 1487; der oberkeit underthan Luther)" (Grimm, 4915). Es decir, en este caso, potestate es traducido ya sea como Gewalt, violencia u Obrigkeit, autoridad, literalmente: entidad superior.

Finalmente, del siguiente verso del Erlkönig, "Und bist du nicht willig/So brauch' ich Gewalt" (Goethe), se conoce la siguiente traducción: "y si no haces caso/usaré la fuerza". El extracto de la balada escrita en 1782 antecede la muerte violenta, forzosa del muchacho, presuntamente como consecuencia de la acción del rey de los alisios.

El recurso a la traducción, en la medida en que convoca al mismo tiempo consideraciones formales y "de contenido", expone de modo tangible los problemas inherentes a todo intento por clausurar definitiva e inequívocamente el campo de significación asociado a la palabra Gewalt. Los meandros que se proyectan a partir de la violencia, en lugar de alinearse en un pensamiento único, concluyente, se bifurcan

\footnotetext{
${ }^{10}$ La traducción de la Biblia hecha por Luther al alemán, tarea que lo absorbería hasta el final de su vida, es conocida por su consideración de los modos populares del decir y su sensibilidad para con la lengua volksnah, es decir, cercana al pueblo. Su traducción actualmente es considerada como precursora del neuhochdeutsch y contribuyó significativamente a la ampliación del vocabulario.
} 
incesantemente, se repliegan sobre sí y, una vez extraviados, se vuelven a entremezclar. No obstante, los recovecos de la enmarañada trayectoria de la Gewalt, lejos de sentenciar el fracaso de la incursión en el lenguaje, confirman nuestra hipótesis original respecto de la contextura y de la naturaleza desustancializada de la violencia.

\section{c. Fisuras en el círculo: Violencia ética}

No obstante, el círculo anteriormente descrito - a través de cuyos vasos sanguíneos se perpetúa y proyecta la Gewalt, de ser necesario hacia el infinito- por muy compacto y consistente que sea no está a salvo de sufrir fisuras o agrietamientos, por medio de los cuales brotan de improviso manifestaciones crudas y embrionarias de violencia. Dichas irrupciones, debido a su intensidad y vehemencia establecen una diferencia no solamente cuantitativa, sino cualitativa con la violencia simbólica contenida, pues emergen de modo inmediato, primario, carente de toda representación sociosimbólica. De acuerdo con dicha hipótesis, aparte de la omnipresencia silente y domesticada de la violencia existirían determinados instantes circunscritos y puntuales en los cuales la violencia acometería de modo radical e importuno. Dichas apariciones fugaces sortearían los controles racionales, legales e institucionales, establecidos con tal de prevenir su embestida, lo que implicaría una aparición desnuda, desprovista de todo ropaje capaz de operar como mediador, buffer o lugarteniente. Enfrentar a la nuda violencia, desguarnecida, palmaria, implicaría enfrentarse a los límites de lo decible, hacer frente a lo que no se deja representar mediante las palabras, soportar la irrupción de lo inconfesable.

A propósito de la citada interrupción del ciclo de la violencia, en Quand Freud voit la mer Goldschmidt parafrasea al célebre dictamen de Adorno y sentencia que de Auschwitz en adelante todo el lenguaje se torna sospechoso. Dicho recelo guarda relación con el hecho de que el exterminio de los judíos, en opinión de Goldschmidt, procedió de modo mudo, silente (stumm), manteniendo y guardando el más estricto mutismo. La complicidad del lenguaje consistiría en el hecho de que ningún discurso anunció, escoltó o mencionó retroactivamente la matanza ocurrida, de modo que la aniquilación de los judíos habría procedido en silencio, silenciándose (schweigend). El decurso de la extinción requiere del silencio del otro, no como la simple omisión del habla, sino como el acto de guardar silencio, de silenciarse y de hacerse el muerto suprimiendo lo que no se abre paso al dominio del habla. En particular a propósito de Auschwitz es posible constatar que si bien el nombre del complejo es evocado una y otra vez — casi de modo mecánico — y que la palabra "Auschwitz" es repetida hasta la saciedad - hasta el punto de extraviarse su sentido-, el decir humano no ha logrado aprehender el horror espeluznante asociado al acontecimiento que refiere. Según el escritor, ensayista y traductor franco-alemán anteriormente mencionado es como si el tejido del lenguaje hubiera sido desgarrado mediante el estallido de aquel acontecimiento espeluznante, incluso como si la textura que es el lenguaje hubiese desaparecido por completo, producto de una fagocitación voraz e insaciable. El silencio que ha seguido a Auschwitz tanto de lado de las ciencias históricas como de las ciencias 
sociales hace pensar a posteriori en un acontecimiento disruptivo y radical, tan monstruoso, tan cruel y tan inhumano que en virtud de su misma consistencia se resiste a hacerse palabra, no deja inscribirse en la dimensión del lenguaje. La conclusión de este razonamiento es que como consecuencia de la sustracción forzosa de Auschwitz al ámbito de las palabras habría ocurrido no solo la desaparición quirúrgica definitiva sin dejar huellas mnémicas o trazos en el lenguaje de las víctimas del exterminio, sino que con ellos habrían desaparecido incluso las mismas palabras.

En relación con dicho silenciamiento y sus consecuencias lacerantes para el lenguaje, Goldschmidt se interroga por la consistencia de lo que él denomina l'impensé radical. En ese contexto se pregunta si Auschwitz acaso no sería el fondo "más profundo" de la técnica y, con ello, de la cultura occidental moderna. La pregunta por Auschwitz se volvería tan escabrosa y delicada, sobre todo porque apunta —e incluso pondría al descubierto- el fondo ominoso y destructivo de la razón occidental, su aplastante incapacidad para establecer una relación con el otro que no se resuelva de modo sistemático en sometimiento o en exterminio. A pesar de la producción constante y consumada al ritmo cadencioso de la marea de una inagotable serie de publicaciones sobre la Segunda Guerra Mundial en general y los campos de concentración en particular, a propósito de Auschwitz - como ya fue señalado por Edmund Husserl en Krisis der europäischen Wissenschaften und die transzendentale Phänomenologie (1936) - se ha instalado un gran y pesado silencio. Al respecto, Goldschmidt señala que el texto Individuum und Terror, publicado originalmente en alemán por Leo Löwenthal en 1945, aun no habría sido traducido ni al castellano ni al francés. Sin embargo, el ejemplo más notorio y el más comentado ha sido el tenaz silencio del pensador de Messkirch. Martin Heidegger, quien ha señalado de forma reiterada que el "olvido" del cual sería culpable occidente, no tuvo ni una sola palabra para nombrar a los olvidados ni para Celan, Hannah Arendt o Jaspers. Más que representar una omisión casual, un descuido fortuito o una negligencia accidental, su complicidad consiste justamente en su silencio, el que se convierte en un silenciamiento cómplice. Lo demás, esto es, el discurso del rectorado de 1933, las diferentes "evidencias" aportadas por los estudiosos del tema ${ }^{11}$ son bajo esta luz aspectos menores, casi circunstanciales y hasta pueden ser atribuidos al provincianismo, a un error político o a la estupidez del filósofo; lo que no puede obviarse es su silencio posterior.

\section{DISCUSIÓN}

Retomando algunas de las consideraciones iniciales aprovechamos de reiterar que con estos miramientos de la violencia no se trata de contribuir a la escritura interminable de uno de tantos panegíricos de lo inefable del lenguaje, su lugar indecible, su punto ciego en el cual convergen lo indecible y lo inenarrable. Es decir, no se trata de invocar el lugar

\footnotetext{
${ }^{11}$ Véase, por ejempo, Lacoue-Labarthe, Philippe. "Sobre el libro de Víctor Farías Heidegger y el nazismo". La ficción de lo político. Madrid: Arena Libros, 2002, pp. 139-156 y Lyotard, Jean-François. Heidegger et les juifs. París: Galilée, 1988.
} 
oscuro, enigmático, impenetrable del lenguaje y sumarse al coro polifónico de las loas de sus núcleos indecibles e inenarrables que se resisten a toda representación. Más bien se trata de explorar - a propósito del plexo de relaciones que pueda ser establecido entre la violencia, por un lado, y el lenguaje, por el otro- mediante un análisis de diferentes fragmentos entrelazados por sus respectivas relaciones de contigüidad, qué lugar o función le correspondería a lo indecible de la violencia. De particular interés ha resultado la discusión de la distinción entre las relaciones entre violencia y lenguaje, en primer lugar, y entre violencia y lengua, por el otro.

En primer lugar el lenguaje, a pesar de que en tanto medium configura el pensamiento y participa de modo determinante de la apertura de mundo (Welterschliessung), en la medida en que no es un medio inerte, estático e inanimado, no está a salvo de los efectos deletéreos de la violencia. Al momento de emprender el intento de pensar la violencia, el lenguaje se ve afectado tanto por su vehemencia letal como por la imposibilidad de pensar la violencia de manera total, sin residuos. Como consecuencia, la violencia compromete al lenguaje, lo corroe, lo desgasta y además puede embrutecer al hombre constituido en el seno del lenguaje. La relación del lenguaje con la violencia dista de ser biunívoca y escapa a toda explicación que presuponga relaciones de causalidad lineales o determinismos simples. No es que el lenguaje domestique o erradique a la violencia, ni que el terreno de la violencia sea estructuralmente incompatible con los dominios del lenguaje. Más bien, las relaciones entre ambos son plurales, diversas y heterogéneas, $\mathrm{y}$ en ocasiones incluso contradictorias o incompatibles. Es posible conjeturar que lo anterior se debe, en primer lugar, a las propiedades de la violencia, a su carácter plástico y moldeable, y la imposibilidad de reducirla a una forma única. En segundo lugar, lo constatado es imputable a los atributos del lenguaje, en concreto su polisemia y sobredeterminación. Dicha multiplicidad irreductible permite pensar que lo genuinamente horroroso de la violencia no radicaría en el descubrimiento del mal que cobija la lengua, sino que aquello que la convierte en una verdadera pesadilla es percibir, justamente ahí, en aquellas palabras benévolas, políticamente correctas, bienintencionadas, que vehiculizarían el bien, toda la carga de la violencia. Dicha embestida, que se produce de un modo que no cabe calificar sino de ominoso por parte de la violencia es capaz de causar en las palabras un genuino estremecimiento, una conmoción que no pasa sin tener efectos. "Las palabras", escribe Arthur Adamov en su cuaderno de notas de 1938, "esas guardianas del sentido, no son inmortales, no son invulnerables (...). Algunas quizás sobrevivan, otras son incurables (...). Agotadas, roídas, manchadas, las palabras se han vuelto esqueletos de palabras, palabras fantasmas; todos rumian y sin convicción eructan sus sonidos entre dientes" (Adamov en Steiner, 12).

En segundo lugar, respecto de la naturaleza de las lenguas, George Steiner en Después de Babel: aspectos del lenguaje y la traducción (1988), de modo análogo a lo constatado en el caso del lenguaje, recuerda que los idiomas no son entes inertes y estáticos sino organismos vivos. Si vinculamos esta premisa a cierta concepción de lo viviente, para quien la doctrina de las pulsiones es un elemento imprescindible, 


\section{Niklas Bornhauser}

podemos conjeturar lo siguiente: en tanto cuerpos dotados de vida se encuentran sujetos al operar de la pulsión vital, erótica, lo que los provee de proyección, pujanza y, en relación con la violencia, de cierto poder de absorción y crecimiento. No obstante, en la medida en que también se supeditan a la pulsión de muerte es posible conjeturar que pueden experimentar el desgaste, la decadencia y finalmente la muerte. Así lo testimonia la lengua de la administración total o los derroteros de las traducciones de ciertos textos fundacionales o canónicos, a partir de cuya lectura se desprenden incontables e inextricables proyecciones. Más allá de las relaciones sostenidas con el lenguaje en general, la violencia se abre paso de modo específico e inconfundible en cada lengua, dependiendo de las propiedades de cada una de ellas y de los modos de violencia que habilita o excluye ya sea a priori o mediante sus posibilidades y restricciones particulares. Por consiguiente, no es posible hablar de la violencia como tal o en sí, abstrayéndose de la respectiva lengua de origen, sino que habría que atender, procediendo caso a caso, a las múltiples inscripciones de la violencia en el dominio propio que es cada lengua.

Las reflexiones precedentes, por muy desgarradas e inconclusas que puedan parecer, más allá de las numerosas indicaciones respecto de las orientaciones y los sentidos de la problematización de la violencia, nos alertan contra el peligro del silenciamiento - al mismo tiempo sigiloso y vehemente - de las palabras y su remplazo por la fraseología vacía, las habladurías (Gerede), la charlatanería insípida e insulsa; todos ellos presagios del imperio de una jerga tecnologizada y deshumanizada. Las posibilidades de resistencia, sostenidas en la apuesta a la indocilidad reflexiva, se juegan no solamente en la denuncia de la banalización y de la reducción a la unidimensionalidad del lenguaje y de las lenguas, sino en la defensa de la sobrevivencia de sus dimensiones vitales, promotoras de la vida, en "tiempos de escasez".

$$
\begin{array}{r}
\text { Universidad Andrés Bello* } \\
\text { Escuela de Psicología } \\
\text { Fernández Concha 700, Santiago (Chile) } \\
\text { niklas.bornhauser@gmail.com }
\end{array}
$$

\section{OBRAS CITADAS}

Agamben, Giorgio. Estado de excepción. Buenos Aires: Adriana Hidalgo, 2004.

__ "Qué es un campo". Rescatado el 13 de diciembre de 2013. Disponible en: $\mathrm{http} / /$ www.egs.edu/faculty/giorgio-agamben/articles/que-es-campo/

Baudelaire, Charles. "La Modernité", Le Peintre de la vie moderne, Euvres complètes. Paris: Gallimard, 1951.

Biblia Plenitud (Versión Reina Valera, 1960). Ed. Jack W. Hayford. Miami: Editorial Caribe, 1994.

Bosworth, Joseph y Thomas Northcote Toller. An Anglo-Saxon Dictionary. Oxford: Clarendon Press, 1898. 
Butler, Judith. The Psychic Life of Power. Theories in Subjection. Stanford: StanfordUniversity Press, 1997.

Claro, Andrés. El contrato de transporte y el naufragio del sentido: las concepciones lingüístico-trascendentales de W. von Humboldt. Grifo, 21(2011): 19-23.

Foucault, Michel. El poder psiquiátrico Curso del Collège de France (1973-1974). Buenos Aires: Fondo de Cultura Económica, 2005

"El sujeto y el poder". Michel Foucault: más allá del estructuralismo y la hermenéutica. Eds. Dreyfus, Hubert L. y Rabinow, Paul. Buenos Aires: Nueva Visión, 2001: 242-259.

Defender la sociedad. Curso del Collège de France (1975-1976). Buenos Aires: Fondo de Cultura Económica, 2000.

"Qu'est-ce que la critique? (Critique et Aufklärung)", Bulletin de la Société française de philosophie, abril-junio (1990): 35-63.

Freud, Sigmund. "Nuevas conferencias de introducción al psicoanálisis. 31"a conferencia. La descomposición de la personalidad psíquica". Obras Completas, Vol. XXII. Buenos Aires: Amorrortu, 1979: 53-74.

Goethe, Johann Wolfgang von. "Der Erlkönig". Berliner Ausgabe. Poetische Werke, tomo 1. Berlin/Weimar: Aufbau, 1960: 115-116.

Goldschmidt, Georges-Arthur. Quand freud voit la mer. Freud et la langue allemande. Paris: Buchet Chastel, 1988.

Grimm, Jacob und Grimm, Wilhelm. Deutsches Wörterbuch von Jacob und Wilhelm Grimm. 16 tomos. Leipzig: S. Hirzel, 1971.

Heitmeyer, Wilhelm yHagan, John (ed). Internationales Handbuch der Gewaltforschung. Wiesbaden: Westdeutscher Verlag, 2002.

Husserl, Edmund. Krisis der europäischen Wissenschaften und die transzendentale Phänomenologie. $3^{\mathrm{a}}$ edición. Hamburg: Felix Meiner Verlag, 1996.

Lacoue-Labarthe, Philippe. "Sobre el libro de Víctor Farías Heidegger y el nazismo". La ficción de lo político. Madrid: Arena Libros, 2002: 139-156.

Röttgers, Kurt y Saner, Hans (ed.). Gewalt: Grundlagenprobleme in der Diskussion der Gewaltphänomene. Basel/Stuttgart: Schwabe, 1978.

Schmidt, Arno. Der Platz, an dem ich schreibe: 17 Erklärungen zum Handwerk des Schriftstellers. Zürich: Haffmans, 1993.

Sofsky, Wolfgang. Traktat über die Gewalt. Frankfurt a. M.: S. Fischer, 1996.

— Die Ordnung des Terrors: Das Konzentrationslager. Frankfurt a. M.: S. Fischer, 1993.

— Die Ordnung sozialer Situationen. Theoretische Studien über die Methoden und Strukturen sozialer Erfahrung und Interaktion. Opladen: Westdeutscher Verlag, 1983.

Steiner, George. After Babel. Aspects of translation. Oxford: Oxford University Press, 1998.

Žižek, Slavoj. El espinoso sujeto. El centro ausente de la ontología política. Barcelona: Paidós, 2001. 